\title{
Article
}

\section{Microchimerism and transmission of porcine endogenous retrovirus from a pig cell line or specific pathogen-free pig islets to mouse tissues and human cells during xenografts in nude mice}

\author{
B. Clémenceau, D. Jégou, L. Martignat, P. Saï \\ Cellular and Molecular Immuno-Endocrinology, INRA/ENVN/University, Nantes, France
}

\begin{abstract}
mice, 7 were positive for PERV (3 lymph nodes, 1 kidney, 2 salivary glands, 1 ovary), and 14 were Aims/hypothesis. Pig islets could transmit porcine endogenous retroviruses (PERV) to diabetic patients. Our previous work showed that pig islets expressed low levels of PERV mRNA and were not likely to transmit PERV to human cells in vitro. The real risk of infection during pig tissue xenografts can only be evaluated by in vivo experiments.

Methods. Nude mice bearing tumours containing human 293 cells were grafted with specific pathogenfree pig islets or PERV-producing pig PK15 cells to determine whether pig cells could transmit PERV to mouse and human cells in vivo. Infection was monitored by PCR, long PCR, RT-PCR and long RT-PCR. As detection of PERV sequences could be due to the presence of residual pig cells, we looked for pig mitochondrial (mt) DNA. Quantitative PCR for PERV and pig mt DNA was done to compare the PERV-topig $\mathrm{mt}$ (P-to-M) ratio of each sample with the reference ratio for grafted pig cells.

Results. Among 78 mouse tissues from PK15-grafted mice, 54 and 72 were positive for gag and pig mt DNA, respectively. Human tumours developed positive for pig mt DNA. Three of these samples (1 lymph node, 1 kidney and 1 salivary gland) were positive for gag DNA, but negative for pig mt DNA. One human tumour in these mice was positive for PERV DNA. P-to-M reference ratio in grafted islet cells was $0.05 \pm 0.03$. The three PERVpositive lymph nodes contained $78 \mathrm{gag} / 3 \mathrm{mt}$ copies (P-to-M: 26), 101 gag/3 mt copies (P-to-M: 34), and $4 \mathrm{gag} / 0 \mathrm{mt}$ copies. The two PERV-positive salivary glands contained $14 \mathrm{gag} / 1 \mathrm{mt}$ copies, and $28 \mathrm{gag} / 0 \mathrm{mt}$ copies. The ovary and the kidney contained $46 \mathrm{gag} /$ $3 \mathrm{mt}$ and $69 \mathrm{gag} / 0 \mathrm{mt}$ copies, respectively. The PERV-positive human tumour contained $47 \mathrm{gag} / 3 \mathrm{mt}$ copies.

Conclusions/interpretation. Microchimerism and PERV transmission were frequently observed in both mouse and human tissues during grafting of pig PK15 cells into nude mice bearing human tumours, and sometimes during pig islet xenograft in this model. This strengthens the notion that there is a risk of transmitting PERV during pig islet xenograft. [Diabetologia (2002) 45:914-923]
\end{abstract} in these mice were positive for PERV (78\%) and pig $\mathrm{mt}(89 \%)$. The P-to-M ratios for mouse tissues and PERV-positive human tumours from PK15grafted mice were higher than the ratio in PK15 cells. Among 41 tissues from pig islet cell-grafted

Keywords Xenograft, pig endogenous retrovirus, pig islet cell, PK15 cells, specific pathogen free pig, human cells, mouse.

Received: 21 November 2001 / Revised: 6 February 2002

Published online: 15 May 2002

C) Springer-Verlag 2002

Corresponding author: Dr. P. Saï, Immuno-endocrinology, ENVN, Atlanpole, La Chantrerie, BP 40706, 44307 Nantes cedex 3, France, e-mail: sai@vet-nantes.fr
Abbreviations: SPF, Specific pathogen free; bp, base pair; COII, Cytochrome Oxidase subunit II; mt DNA, mitochondrial DNA; PCR, Polymerase Chain Reaction; PERV, Porcine Endogenous Retrovirus; RT, Reverse Transcriptase; PERT, Product Enhanced Reverse Transcriptase Test 
During xenograft, there is a risk of transmitting infectious agents from pig to man. The risk of conventional zoonosis led us to isolate islets from specific pathogen-free (SPF) pigs [1, 2, 3, 4, 5, 6, 7, 8]. However, there is also a risk of transmitting porcine endogenous retroviruses (PERV) [9, 10, 11, 12]. The ability of PERV [10] produced by pig cells to infect human cells in vitro has been documented $[8,9,13,14,15,16$, 17]. PERV mRNA and full-length endogenous retroviral genome were expressed in all pigs tested $[9,15$, $18,19]$, including SPF pigs [5, 20]. Thus, the use of SPF pigs does not seem to be able to prevent PERV transmission to xenograft recipients.

The actual risk of infection during pig tissue xenograft can only be evaluated convincingly by in vivo experiments. Investigations in baboons [21, 22, 23] and patients transplanted or dialysed with pig tissues [24, 25, $26,27,28,29,30]$ failed to detect transmission of pig retroviruses. Some studies have suggested that PERV could be transmitted to mice after pig islet xenograft $[31,32]$ but other results are contradictory [30, 33].

Although the risk of transmitting PERV can be evaluated independently of the type of pig tissue grafted, it also needs to be analysed specifically for a given tissue. The risk of transmission could depend on viral load, as in the case of other retroviral infections [34]. Our previous work showed that pancreas expressed the lowest levels of PERV mRNA in SPF pig tissues intended for grafting [5], and that long-term follow-up failed to detect in vitro transmission of PERV from SPF pig islets to a panel of human cells, even after repeated and optimised co-incubations [8].

In this study, a model was designed to investigate whether SPF pig islets transmit PERV sequences to human cells in vivo as well as to mouse tissues. Nude mice bearing a subcutaneous tumour produced by injection of highly PERV-sensitive cells of the human 293 line were grafted with SPF pig islets or PERVproducing pig PK15 cells. Infection of mouse tissues and human cells was monitored by PCR and RT-PCR to detect PERV DNA and RNA for gag, pol and the three env sub-types (A, B and C) [9, 13, 18]. Long PCR and RT-PCR were done to detect full-length PERV proviruses and genomic RNA [20]. As detection of PERV sequences in the mouse or human cell extracts could be due to the presence of residual pig cells (microchimerism) and not to true infection, sensitive and specific detection of pig mitochondrial (mt) DNA was carried out to avoid misinterpretation. Realtime quantitative PCR for PERV and pig mtDNA was carried out to compare a PERV/pig mt ratio calculated for each mouse or human sample with the reference ratio obtained for grafted pig cells.

\section{Materials and methods}

Specific pathogen-free (SPF) pig islet cells, porcine retrovirusproducing cell lines, and human target cells. Islets were pro- vided by E. Gouin (Ploufragan and Nantes, France) from Large-White SPF pigs (80-120 kg), aged 20 weeks, as previously described [1, 2]. Pancreases were removed in betadine solution and inflated with $100 \mathrm{ml}$ ice-cold sterile modified University of Wisconsin (mUW) solution and transported in mUW. Pancreases were then inflated again with $0.5 \mathrm{ml} / \mathrm{g}$ of $\mathrm{mUW}$ solution containing $2 \mathrm{mg} / \mathrm{ml}$ Liberase (Roche Diagnostics, Meylan, France) and placed in a digestion chamber filled with mUW solution kept at $36^{\circ} \mathrm{C}$. Crude islets were pelleted by centrifugation, suspended in mUW and purified on continuous Optiprep gradient (Life International Technology, Cergy-Pontoise, France) with a COBE 2991 processor. Islet purity, as assessed by dithizone staining, exceeded $90 \%$. This isolation provided islets capable of reacting to nutriments, hormones and neuromediators [2]. Islets were treated with EDTA and dispase to obtain islet cell suspensions. Islet cells were numerated and suspended in Ham's F10 medium $(5.5 \mathrm{mmol} / \mathrm{l} \mathrm{glu-}$ cose) (Biomédia, Boussens, France) supplemented with 2\% Ultroser (BioSepra, Villeneuve la Garenne, France).

PERV-producing PK15 were provided by Dr E. Albina (AFSSA, Ploufragan, France) and cultured in Modified Eagle's Medium (MEM) containing 10\% fetal calf serum (FCS), $2 \mathrm{mmol} / \mathrm{l}$ glutamine, $1 \mathrm{mmol} / \mathrm{l}$ sodium pyruvate, $100 \mathrm{U} / \mathrm{ml}$ penicillin and $100 \mathrm{mg} / \mathrm{ml}$ streptomycin.

293 human embryonic kidney cells (CRL-1573), a PERVsusceptible cell line (provided by Dr N. Ferry, Nantes, France) were maintained in Dulbecco's modified Eagle's medium supplemented with $10 \% \mathrm{FCS}$ and $2 \mathrm{mmol} / \mathrm{l}$ glutamine.

Simultaneous xenografts of human 293 cells and PERV-producing pig PK15 cells or SPF pig islet cells in nude mice. Female NMRI nude mice (Janvier, Le Genest-St-Isle, France) were injected subcutaneously on two occasions (two weeks apart) with $50 \times 10^{6}$ PK15 cells in the right flank, and then, 6 weeks after the initial injection, with $30 \times 10^{6}$ human 293 cells in the left flank. All tumours were finally apparent at the inoculation site, and no metastases were observed. Tumours induced by human 293 cells appeared 3 to 4 weeks after injection, and those induced by PK15 cells 3 months after injection. Other nude mice irradiated $24 \mathrm{~h}$ before (750 Gy) were similarly grafted with human 293 cells in the left flank and then, after 2 weeks, with $6 \times 10^{6} \mathrm{SPF}$ pig islet cells intraperitoneally. All mice were killed 2 months after the pig grafts. Evidence that at least part of the pig islet cells had survived at the time of killing was supported by the detection and separation of porcine insulin in the sera of the mice by reverse phase HPLC [35]. The elution time profile obtained with sera from mice grafted with pig islet cells revealed a peak of insulin eluting at the position of porcine insulin standard, in addition to mouse I and II insulins. Only the two mouse insulin peaks were detected in plasma from control mice. DNA and RNA were extracted from porcine and human cells and from different mouse tissues using the QIAamp DNA blood mini-kit and the RNeasy mini-kit, respectively (QIAGEN, Courtaboeuf, France). Total RNA was treated with Rnase-free DNase I (Roche Diagnostics) for $30 \mathrm{~min}$ at $37^{\circ} \mathrm{C}$ to avoid DNA contamination (the efficiency of this DNAase treatment was assessed by RT-PCR performed without the RT step).

PCR-derived monitoring of PERV infection and microchimerism on mouse tissues and human tumours. The primers (Table 1) used for PCR amplification of PERV sequences allow detection of full-length PERV and fragments of 3 retroviral genes. These three genes called gag, pol, env, encode capsid proteins, retroviral enzymes, and envelop glycoproteins, respectively. The primers used for PCR amplification of PERV sequences or pig mt DNA were synthesised by the Life Tech- 
Table 1. Primer pairs for classic or quantitative real time PCR amplification of PERV and porcine mitochondrial DNA (mtDNA)

\begin{tabular}{|c|c|c|c|}
\hline $\begin{array}{l}\text { Region and } \\
\text { Code primers }\end{array}$ & Sequences & $\begin{array}{l}\text { Amplified } \\
\text { product } \\
\text { (pb) }\end{array}$ & References \\
\hline gag & $\begin{array}{l}\text { 5'CCCGATCAGGAGCCCTATATCCTTACGTG-3' } \\
\text { 5'-CGCAGCGGTAATGTCGCGATCTCGT-3' }\end{array}$ & 362 & Akiyoshi et al. 1998 \\
\hline pol & $\begin{array}{l}\text { 5'-GCTACAACCATTAGGAAAACTAAAAG-3' } \\
\text { 5'-AACCAGGACTGTATATCTTGATCAG-3' }\end{array}$ & 326 & Patience et al. 1997 \\
\hline env-A PL 170/171 & $\begin{array}{l}\text { 5'-TGGAAAGATTGGCAACAGCG-3' } \\
\text { 5'-AGTGATGTTAGGCTCAGTGG-3' }\end{array}$ & 361 & Le Tissier et al. 1997 \\
\hline env-B PL 172/173 & $\begin{array}{l}\text { 5'-TCCTCCTTTGTCAATTCCGG-3' } \\
\text { 5'-TACTTTATCGGGTCCCACTG-3' }\end{array}$ & 265 & Le Tissier et al. 1997 \\
\hline env-C PL 205/206 & $\begin{array}{l}\text { 5'-CTGACCTGGATTAGAACTGG-3' } \\
\text { 5'-ATGTTAGAGGATGGTCCTGG-3' }\end{array}$ & 280 & Takeuchi et al. 1998 \\
\hline PERV Long PCR & $\begin{array}{l}\text { 5'-ACGTGCTAGGAGGATCACAGGCTGC-3' } \\
\text { 5'-GTTGTCTAAGTACCATGATCTGGACTGCAC-3' }\end{array}$ & 7200 & Bösch et al. 2000 \\
\hline mt DNA PMTF2/PMTR2 & $\begin{array}{l}\text { 5'-TCACCCATCATAGAAGAACTCCTACA-3' } \\
\text { 5'-TTTTACGGTTAAGGCTGGGTTATTAAT-3' }\end{array}$ & 255 & Switzer et al. 1999 \\
\hline PERV gag (quantitative PCR) & $\begin{array}{l}\text { 5'CCGAGTGTTTGTTTTTCTCTCCAA3' } \\
\text { 5'CCGAGTGTTTGTTTTTCTCTCCAA3' }\end{array}$ & 70 & \\
\hline Porcine mtDNA (quantitative PCR) & $\begin{array}{l}\text { 5'TGAACAATCCTACCCGCTATTATTC 3' } \\
\text { 5' TACGGTTAAGGCTGGGTTATT3' }\end{array}$ & 99 & \\
\hline Porcine $\beta$ globin (quantitative PCR) & $\begin{array}{l}\text { 5'TGCACAAACAGACAACATGG 3' } \\
5^{\prime} \text { TTCGTCCACATTCACTTTGC 3' }\end{array}$ & 85 & \\
\hline
\end{tabular}

nologies system (Cergy Pontoise, France). PCR was done on GeneAmp PCR System 9700 (PE Applied Biosystems, Foster City, Calif., USA). Species-specificity of the primers was checked for the absence of signals on samples from mouse or human cells. In all experiments, $15 \mu \mathrm{l}$ of amplification products were visualised on $2 \%$ agarose gels after ethidium bromide staining.

Detection of pig specific cellular DNA. Detection of a 255 bp sequence from the pig mt DNA cytochrome oxidase subunit II (COII), using primers PMTF2 and PMTR2 [36], was done to evaluate the presence of pig cellular DNA (microchimerism) in mouse or human cells. PCR was performed with $0.75 \mu \mathrm{g}$ of DNA in $50 \mu \mathrm{l}$ reaction buffer $(10 \mathrm{mmol} / \mathrm{l}$ Tris- $\mathrm{HCl}, \mathrm{pH} 8.3$, $50 \mathrm{mmol} / \mathrm{l} \mathrm{KCl}, 1.1 \mathrm{mmol} / \mathrm{l} \mathrm{MgCl}{ }_{2}, 0.01 \%$ gelatin), $200 \mu \mathrm{mol} / \mathrm{l}$ of each dNTP (Promega, Madison, Wis., USA), 2.5 U Red-Taq polymerase (Sigma, St. Louis, Miss., USA) and $0.5 \mu \mathrm{mol} / 1$ of each primer. The PCR conditions were: $94^{\circ} \mathrm{C}$ for $4 \mathrm{~min}, 94^{\circ} \mathrm{C}$ for $30 \mathrm{~s}$, annealing at $56^{\circ} \mathrm{C}$ for $30 \mathrm{~s}$, and $72^{\circ} \mathrm{C}$ for $30 \mathrm{~s}(40 \mathrm{cy}-$ cles). A final elongation step was performed at $72^{\circ} \mathrm{C}$ for $10 \mathrm{~min}$.

Detection of PERV DNA by PCR. PCR were performed as described above, except for the following points: $1 \mu \mathrm{g}$ of DNA were used; annealing temperature was $56^{\circ} \mathrm{C}$ for pol and gag, $57^{\circ} \mathrm{C}$ for env- $\mathrm{A}$ and env-B, and $63^{\circ} \mathrm{C}$ for env-C; and the number of cycles was modified to 60 or 40,30 and 35 , respectively. To evaluate the sensitivity of PCR for $g a g$, pol, and env, DNA was extracted from mixtures of pig PK15 cells and mouse or human cells $(n=3)$, and serial dilutions were obtained. PCR for $g a g, p o l, e n v-A$ and $e n v-B$ were still positive with DNA dilutions corresponding to the equivalent of $0.1,1.0,0.15$ and 0.3 PK15 cells, respectively, in the background of mouse or human DNA. During experiments with the same samples, PCR for pig COII mt DNA was at least 40 times more sensitive, as it was still positive with $0.025 \mathrm{pg}$ DNA (vs $2.5 \mathrm{pg}$ for gag PCR).
Detection of PERV proviruses. Long PCR on PERV sequences has been previously described [20]. Amplification was performed with the Platinum Taq High Fidelity system (Life Technologies). The primers amplified a $7.2 \mathrm{~kb}$ fragment from all PERV-A, -B, or -C sequences.

Detection of PERV mRNA by RT-PCR. Reverse transcription was performed for $1 \mathrm{~h}$ at $42^{\circ} \mathrm{C}$ using $1 \mu \mathrm{g}$ of RNA in an $40 \mu \mathrm{l}$ reaction buffer $(50 \mathrm{mmol} / \mathrm{l}$ Tris- $\mathrm{HCl}, \mathrm{pH} 8.3,75 \mathrm{mmol} / \mathrm{l} \mathrm{KCl}$, $3 \mathrm{mmol} / \mathrm{l} \mathrm{MgCl} 2,10 \mathrm{mmol} / \mathrm{l} \mathrm{DTT})$, with $400 \mathrm{U}$ of M-MLV-RT (Promega), $1 \mathrm{mmol} / \mathrm{l}$ deoxynucleoside triphosphate (Promega), $40 \mathrm{U}$ of RNase inhibitor (Promega), and 0.04 U. D.O. of $\operatorname{pd}(\mathrm{N})_{6}$ (Pharmacia Biotech, Uppsala, Sweden). Thirteen microlitres of cDNA templates were amplified with pol, gag, env$A$, env-B or $e n v-C$ primers in the conditions described above. Control reactions with no reverse transcriptase were performed to check for the absence of residual genomic DNA. Reverse transcription of pig islet RNA was performed with the Sensiscript reverse transcriptase kit (QIAGEN).

Detection of full-length PERV. PERV genomic RNA were retrotranscribed with the Thermoscript RT-PCR system (Life Technologies). The resulting RNase H-treated cDNA, or cellular DNA, were subjected to PCR with the Platinum Taq High Fidelity system (Life Technologies). Using the primers mentioned above, a $7.2 \mathrm{~kb}$ product and fragments of about $3 \mathrm{~kb}$ were produced. Products from long PCR and RT-PCR were transferred to Hybond-N+ nylon membranes (Amersham Pharmacia Biotech, Orsay, France) by Southern blot transfer. Membranes were hybridised with alkaline phosphatase-labelled "gag" probes using the AlkPhos Direct Labelling and Detection systems (Amersham Pharmacia). After washes, membranes were incubated with the CDP-star chemiluminescent detection reagent and exposed to X-ray film. 
Real-time quantitative PCR and the PERV/pig COII mt ratio. Quantitative PCR was performed to distinguish the persistence of porcine material (microchimerism) from true infection by PERV in grafted mice. The determination of copy numbers of PERV-gag and pig mt COII sequences allowed comparison of a PERV-to-pig mt (P-to-M) ratio calculated for each mouse or human sample with the reference ratio for grafted pig cells. Quantitation of PERV sequences, using a fluorescence-based, realtime GeneAmp 5700 sequence detection system (Applied Biosystems, Foster City, Calif., USA), was performed in $25 \mu \mathrm{l}$, with the 2X Real-time Sybr Green I mix (Eurogentec, Seraing, Belgium) containing Goldstar DNA polymerase, uracil-N-glycosylase, dNTPs, $5 \mathrm{mmol} / \mathrm{I} \mathrm{MgCl}_{2}$ and Sybr Green. Preliminary tests showed that the optimal concentration for each primer pair was $300 \mathrm{nmol} / \mathrm{l}$ (Table 1). The amount of DNA in each sample was carefully measured by spectrophotometry at $260 \mathrm{~nm}$. One $\mu \mathrm{g}$ of DNA was used in each test (performed in triplicate). Cycling parameters were $2 \mathrm{~min}$ at $50^{\circ} \mathrm{C}, 10 \mathrm{~min}$ at $95^{\circ} \mathrm{C}, 4015$-s cycles at $95^{\circ} \mathrm{C}$, and $1 \mathrm{~min}$ at $60^{\circ} \mathrm{C}$. Standard curves were constructed for gag and mt DNA, using serial tenfold dilutions ( $10^{5}$ to 10 copies for each reaction) of plasmids containing the gag or mt insert. The corresponding threshold cycles $(\mathrm{Ct})$ were recorded, and each point on the curve was the mean of three replications from 10 independent experiments. The sensitivity of this technique allowed detection of two copies of PERV or COII sequences. The conditions required for calculation of $\mathrm{PERV} / \mathrm{mt}$ ratios were: more than two copies for gag or mt sequences; a dissociation curve at the end of the amplification reaction confirming the specific Tm of the amplified product and the absence of primer dimers; and sample $\mathrm{Ct}$ values of 36 or less.

Statistical analysis. Data are presented as mean values \pm SEM. Statistical significances of differences were evaluated using Student's $t$ test or Mann-Whitney test. A $p$ value of less than 0.05 was considered to be statistically significant.

\section{Results}

PERV detection in SPF pig islet cells and pig PK 15 cell line to be grafted. Long PCR amplified full-length DNA from all SPF pig islet preparations tested $(n=6)$, and from PERV-producing PK15 (Fig. 1). RT-PCR and long RT-PCR allowed detection of PERV subgenomic mRNA for gag, pol, env-A and env-B, and fulllength PERV RNA, in PK15 cells ( $n=24$, Fig. 1). In contrast, PERV mRNA for gag, pol, and all three env sub-types (Fig. 1), but no full-length PERV RNA, were found in pig islet cells $(n=8)$. As already reported by us, the expression of all PERV mRNA was much lower in pig islet cells than in PK15 cells [5, 8].

Full-length PERV RNA (long RT-PCR), PERV mRNA (RT-PCR) and RT activity (PERT) were detected in supernatants of PK15 cells $(n=12)$ [5, 8]. In contrast, full-length PERV transcripts and RT activity were never detected in supernatants of SPF pig islet cells $(n=10)$. However, 8 out of 10 pig islet cell supernatants tested were positive for gag mRNA, while 5 and 3 of them were also positive for env-A and env-B, respectively.

$P C R$-derived detection of pig $m t$ and PERV sequences in grafted nude mice. No PCR products were obtained

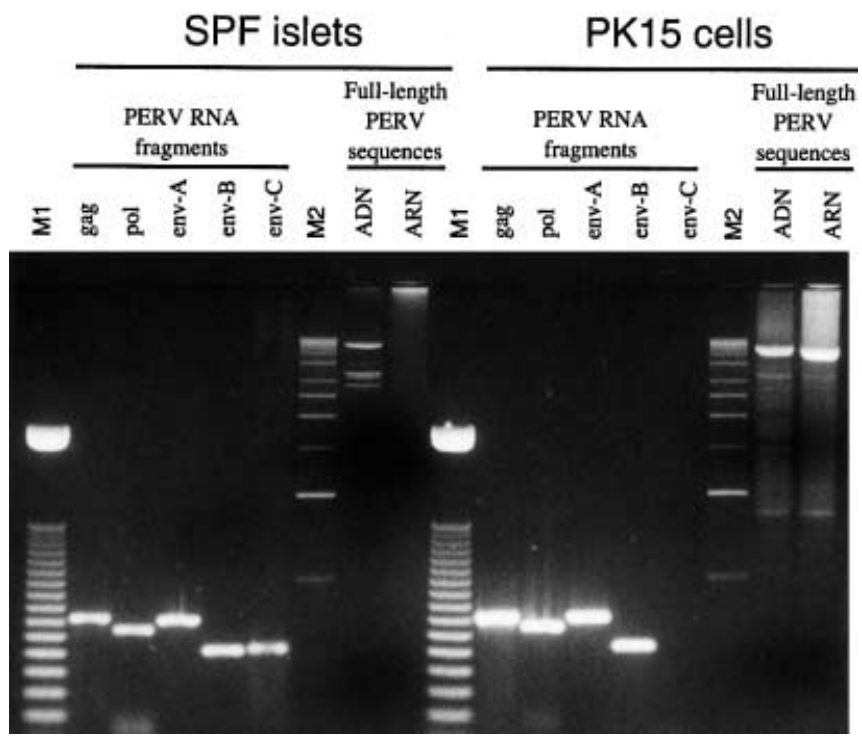

Fig. 1. Detection of PERV mRNA subgenomic fragments (gag, pol, env-A, -B and -C) or full-length PERV sequences in PERV-producing PK15 cells or SPF pig islet cells. For each pig cell type, PERV mRNA fragments or DNA were detected by RT-PCR or PCR. Amplification of a $7.2 \mathrm{kbp}$ full-length provirus (retroviral DNA) and full-length PERV genomic RNA by long-PCR and long RT-PCR, respectively, is also reported. M1 and M2: 50 and $1 \mathrm{Kbp}$ DNA stepladders, respectively

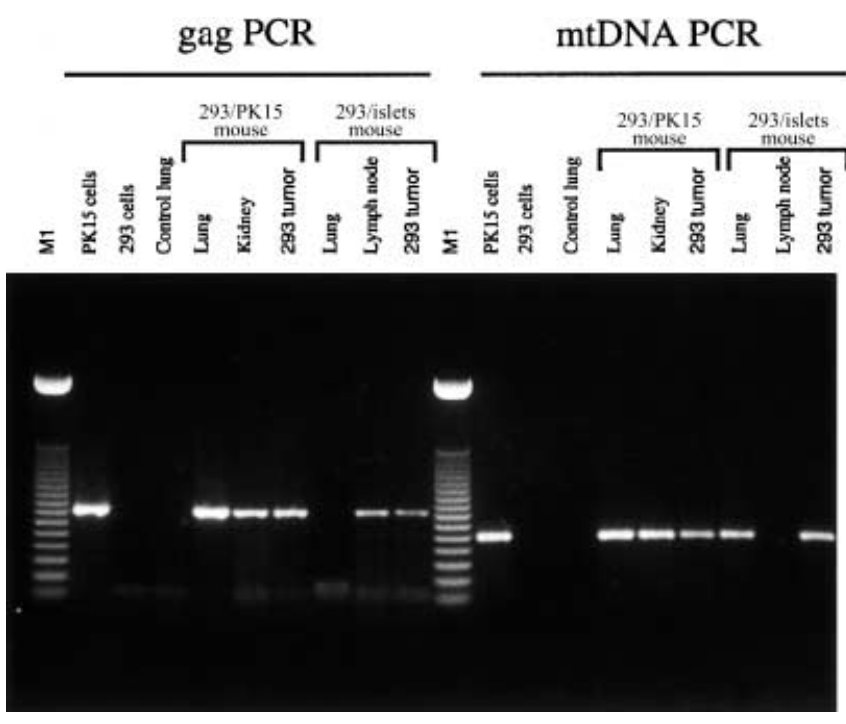

Fig. 2. Representative PCR detection of PERV-gag DNA and pig mitochondrial $(\mathrm{mt})$ COII DNA in nude mouse concomitantly grafted with pig tissues and human 293 cells. The results presented relate to different mouse tissues and human tumours of mice grafted with PERV-producing PK15 cells or pig islet cells. The absence of PCR products in lung from a nude mouse not transplanted with porcine tissues and on "naive" human 293 cells is also shown in each panel. M: 50 bp DNA stepladder

with the mt COII and PERV primers on human 293 cells and a panel of tissues from nude mice not transplanted with pig tissues (representative results are shown in Fig. 2). 
Table 2. PCR for PERV and porcine mt COII DNA in mouse tissues and human 293 tumours of nude mice grafted with either PERV-producing PK15 cells or SPF pig islet cells

\begin{tabular}{|c|c|c|c|c|c|c|c|c|c|c|c|}
\hline & & \multicolumn{5}{|c|}{$\begin{array}{l}\text { Mice grafted with PK15 cells } \\
(n=10)\end{array}$} & \multicolumn{5}{|c|}{$\begin{array}{l}\text { Mice grafted with pig islet cells } \\
(n=5)\end{array}$} \\
\hline & & $\begin{array}{l}\text { Gag } \\
\text { DNA }\end{array}$ & $\begin{array}{l}\text { EnvA } \\
\text { and } \\
\text { EnvB } \\
\text { DNA }\end{array}$ & $\begin{array}{l}\text { Full } \\
\text { length } \\
\text { PERV } \\
\text { DNA }\end{array}$ & $\begin{array}{l}\text { pig mt } \\
\text { COII } \\
\text { DNA }\end{array}$ & $\begin{array}{l}\text { Gag } \\
\text { RNA }\end{array}$ & $\begin{array}{l}\text { Gag } \\
\text { DNA }\end{array}$ & $\begin{array}{l}\text { EnvA } \\
\text { and } \\
\text { EnvB } \\
\text { DNA }\end{array}$ & $\begin{array}{l}\text { Full } \\
\text { length } \\
\text { PERV } \\
\text { DNA }\end{array}$ & $\begin{array}{l}\text { pig mt } \\
\text { COII } \\
\text { DNA }\end{array}$ & $\begin{array}{l}\text { Gag } \\
\text { RNA }\end{array}$ \\
\hline \multirow[t]{11}{*}{$\begin{array}{l}\text { Mouse } \\
\text { tissues }\end{array}$} & $\begin{array}{l}\text { Pig PK15 } \\
\text { tumours }\end{array}$ & $10 / 10$ & $\begin{array}{l}1 / 1 \\
1 / 1\end{array}$ & $5 / 5$ & $10 / 10$ & ND & & & & & \\
\hline & Lungs & $10 / 10$ & $\begin{array}{l}7 / 7 \\
7 / 7\end{array}$ & $5 / 5$ & $10 / 10$ & $6 / 6$ & $0 / 5$ & $\begin{array}{l}0 / 3 \\
0 / 3\end{array}$ & ND & $1 / 5$ & $0 / 3$ \\
\hline & $\begin{array}{l}\text { Lymph } \\
\text { nodes }\end{array}$ & $8 / 9$ & $\begin{array}{l}5 / 8 \\
7 / 9\end{array}$ & $5 / 6$ & $9 / 9$ & $3 / 3$ & $3 / 6$ & $\begin{array}{l}1 / 3 \\
1 / 3\end{array}$ & $2 / 2$ & $2 / 6$ & $0 / 3$ \\
\hline & Blood & $6 / 8$ & $\begin{array}{l}5 / 6 \\
5 / 6\end{array}$ & ND & $6 / 8$ & ND & $0 / 4$ & $\begin{array}{l}0 / 3 \\
0 / 3\end{array}$ & ND & $0 / 4$ & ND \\
\hline & Kidneys & $6 / 9$ & ND & $3 / 4$ & $8 / 9$ & $3 / 3$ & $1 / 5$ & $\begin{array}{l}0 / 3 \\
0 / 3\end{array}$ & $1 / 1$ & $2 / 5$ & $0 / 1$ \\
\hline & Ovaries & $2 / 5$ & ND & ND & $5 / 5$ & ND & $1 / 3$ & $\begin{array}{l}0 / 3 \\
1 / 3\end{array}$ & $0 / 3$ & $2 / 3$ & ND \\
\hline & Testis & $5 / 5$ & ND & $4 / 5$ & $5 / 5$ & $4 / 4$ & $0 / 2$ & ND & ND & $1 / 2$ & ND \\
\hline & $\begin{array}{l}\text { Salivary } \\
\text { glands }\end{array}$ & $7 / 10$ & ND & $4 / 5$ & $10 / 10$ & ND & $2 / 5$ & $\begin{array}{l}1 / 3 \\
0 / 3\end{array}$ & $1 / 1$ & $2 / 5$ & $0 / 2$ \\
\hline & Hearts & $8 / 10$ & ND & $2 / 2$ & $10 / 10$ & $1 / 1$ & $0 / 5$ & ND & ND & $2 / 5$ & ND \\
\hline & Spleens & $1 / 6$ & ND & ND & $5 / 6$ & ND & $0 / 3$ & ND & ND & $1 / 3$ & ND \\
\hline & Livers & $0 / 6$ & ND & ND & $4 / 6$ & ND & $0 / 3$ & ND & ND & $1 / 3$ & ND \\
\hline \multicolumn{2}{|c|}{ Human 293 tumours } & $7 / 9$ & $\begin{array}{l}4 / 5 \\
5 / 5\end{array}$ & $6 / 7$ & $8 / 9$ & $4 / 9$ & $1 / 4$ & $\begin{array}{l}2 / 2 \\
1 / 2\end{array}$ & $0 / 2$ & $3 / 4$ & $0 / 3$ \\
\hline
\end{tabular}

Results indicate numbers of positive PCR samples. ND, not determined

PERV and pig mt sequences in mice grafted with PK15 and human 293 cells. All PK15 pig tumours explanted from grafted nude mice were positive for gag, env-A, env-B and full-length PERV, but also for pig mt sequences (Table 2).

Among 78 mouse tissues from PK15-grafted mice, $54(79 \%)$ were positive for PERV-gag with PCR using high (60) or low (40) cycle numbers (Table 2). All samples which were positive for gag were also positive with PERV-env PCR (data not shown). High positivity frequencies for gag sequences were observed in lung and testis $(100 \%$ positivity for the samples tested), lymph node (89\%), heart (80\%), blood (75\%), salivary gland $(70 \%)$, and kidney $(67 \%)$. Classical PCR provided consistently higher amplification signals for lung and lymph node than for other samples. Other organs displayed lower positivity frequencies for gag, ie. ovary (40\%) and spleen (17\%). Livers of PK15-grafted nude mice were never positive for gag. Gag RNA and full-length PERV DNA were detected in all lung and lymph node samples positive for gag DNA (Table 2). Full-length PERV sequences and even gag mRNA were also detected in most of the gag DNA-positive samples, ie. kidney, testis, salivary gland and heart.

Among the 78 mouse tissues from PK15-grafted mice, 72 (92\%) were positive for pig mt COII sequences (Table 2). High positivity frequencies were found in lung, heart, salivary gland, lymph node, and testis $(100 \%$ positivity for the samples tested). Other organs were positive for pig mt within a range of $67 \%$ (liver) to about $90 \%$ (kidney).

Among 23 mouse samples negative for gag PERV, 19 were positive for pig mt. This was particularly the case for liver and spleen samples (Table 2). Conversely, no mouse samples were positive for gag PERV DNA and negative for pig mt sequences. Only 6/78 mouse samples were negative for both gag and pig COII DNA.

Among the human 293 tumours that developed in nude mice and were simultaneously grafted with PK15 cells, 78\% were positive for gag DNA (Fig. 2, Table 2). Env DNA was also found in these samples. Full-length PERV DNA was detected in all human tu- 
Table 3. Quantitative PCR for PERV-gag and porcine mt COII DNA in mouse tissues and human 293 tumours of nude mice grafted with PERV-producing PK15 cells or SPF pig islet cells. Only gag-positive tissues detected by classical PCR were tested with quantitative PCR. Determination of the copy numbers of
PERV and pig mt sequences allowed comparison of a PERV/pig $\mathrm{mt}$ (P-to-M) ratio calculated for each mouse or human sample with the "reference" ratio for grafted pig cells. As indicated in Materials and methods, P-to-M ratios were only calculated if more than two copies of gag and $\mathrm{mt}$ sequences were found

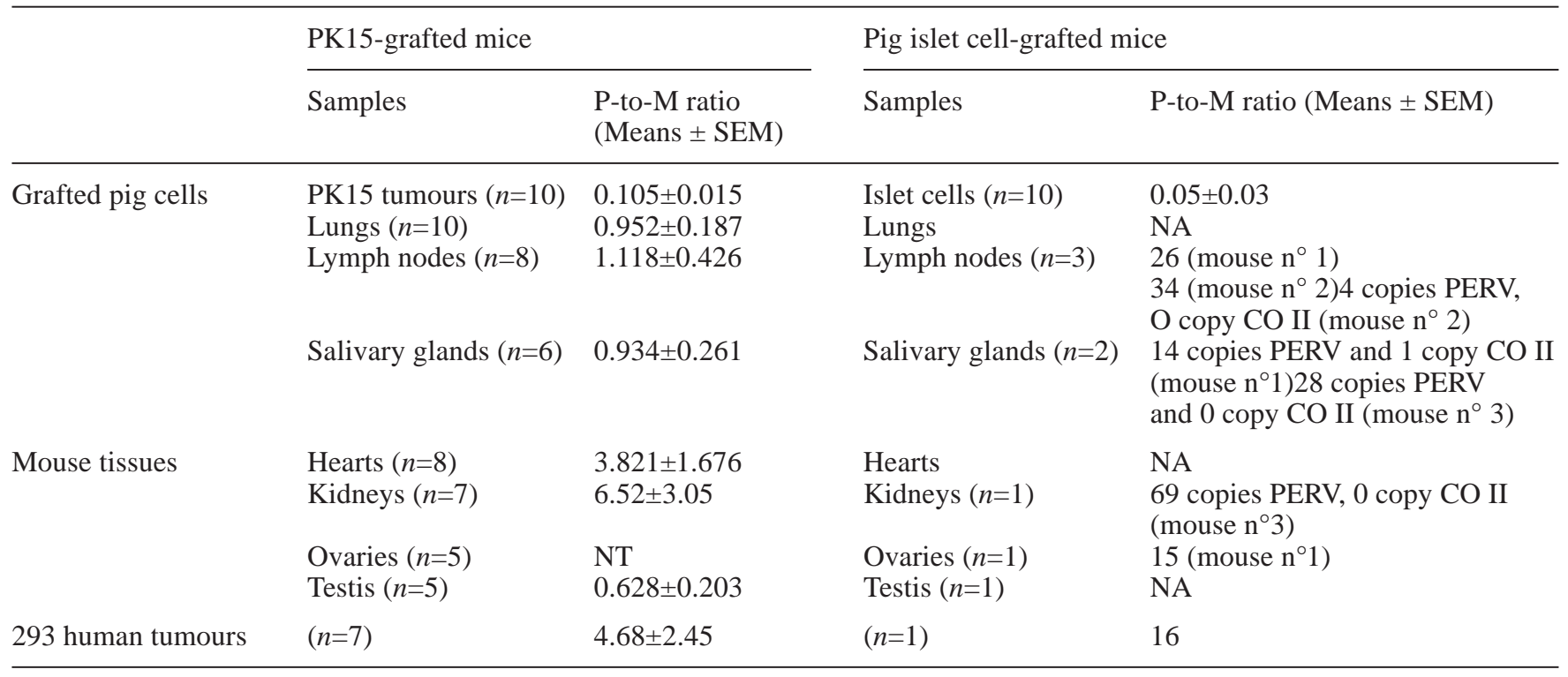

NA, not applicable (no PERV-positive sample available); NT, not tested

mours (except one) positive for both gag and env DNA. Gag RNA was also detected in 4/9 human 293 tumours. Among human tumours positive for gag mRNA, all but one had full-length PERV sequences. Among human tumours, $89 \%$ were positive for pig $\mathrm{mt}$ COII sequences (Fig. 2, Table 2).

PERV DNA and RNA in nude mice grafted with SPF pig islet cells and 293 cells. Some mouse samples (7/41, 17\%) from pig islet cell-grafted mice were positive for PERV-gag DNA with PCR using high (60) or lower (40) cycle numbers (Table 2), and for PERV-env DNA (data not shown). Three lymph nodes out of 6 tested, one kidney, 2 salivary glands, and 1 ovary were positive for gag DNA and full-length PERV DNA. However, no gag-PERV RNA was detected in these samples. In contrast to the high frequency and intensity of PERV positivity in lungs of mice grafted with PK15 cells, all lungs from mice grafted with pig islet cells were negative for gag or env DNA or RNA. All blood, heart, spleen and liver samples of these mice were also PERV-negative.

Among the mouse samples from pig islet cell-grafted mice, several $(14 / 41,34 \%)$ were positive for pig $\mathrm{mt}$ DNA (Table 2).

Of note, three samples from the same mouse positive for PERV-gag DNA were negative for pig mt DNA: 1 lymph node (Fig. 2), 1 kidney and 1 salivary gland. Conversely, 11/41 samples were positive for pig mt DNA and negative for PERV-gag DNA: 2 kidney, 1 salivary gland, 1 ovary, 2 heart, 1 spleen, 1 lung, 1 liver, 1 testis and 1 lymph node. Finally, 21/41 samples (51\%) from pig islet cell-grafted mice were negative for both gag and pig mt DNA.

One sample of human 293 tumour recovered from pig islet cell-grafted mice was positive for PERV-gag DNA (Table 2, Fig. 2), as confirmed for env DNA. This tumour was obtained from a mouse that also had two gag-positive lymph nodes. Given the size of this 293 tumour (about $2 \mathrm{~cm}$ in diameter), two other biopsies from other regions were analysed but failed to confirm gag positivity. None of the three tested samples revealed gag RNA or full-length PERV (Fig. 2, Table 2). All 293 tumours but one (including the PERV-positive tumour) were positive for pig $\mathrm{mt}$ sequences.

Real-time quantitative PCR for pig $m t$ and PERV sequences in grafted nude mice. PERV and mitochondrial sequences in PK15 tumours explanted from nude mice numbered $2343 \pm 884$ and $19721 \pm 7042$ for each ng of DNA, respectively (Fig. 3). The corresponding P-to-M ratio of $0.105 \pm 0.015$ was used as the reference ratio for comparisons.

The mean P-to-M ratios in all mouse tissues from PK15-grafted mice were higher than the reference ratio: lung $(0.952 \pm 0.187 ; p \leq 0.005)$, heart, salivary gland and lymph node $(3.821 \pm 1.676,0.934 \pm 0.261$, and $1.118 \pm 0.426$, respectively; $p \leq 0.04)$, testis, and kidney $(0.628 \pm 0.203$, and $6.52 \pm 3.05$, respectively; $p \leq 0.05$ ) (Table 3). For example, all lungs and 7/9 lymph nodes tested had a P-to-M ratio higher than the mean value +3 SD of the ratios for PK15 tumours.

Among the human 293 tumours that developed in PK15-grafted mice, only the seven gag-positive sam- 

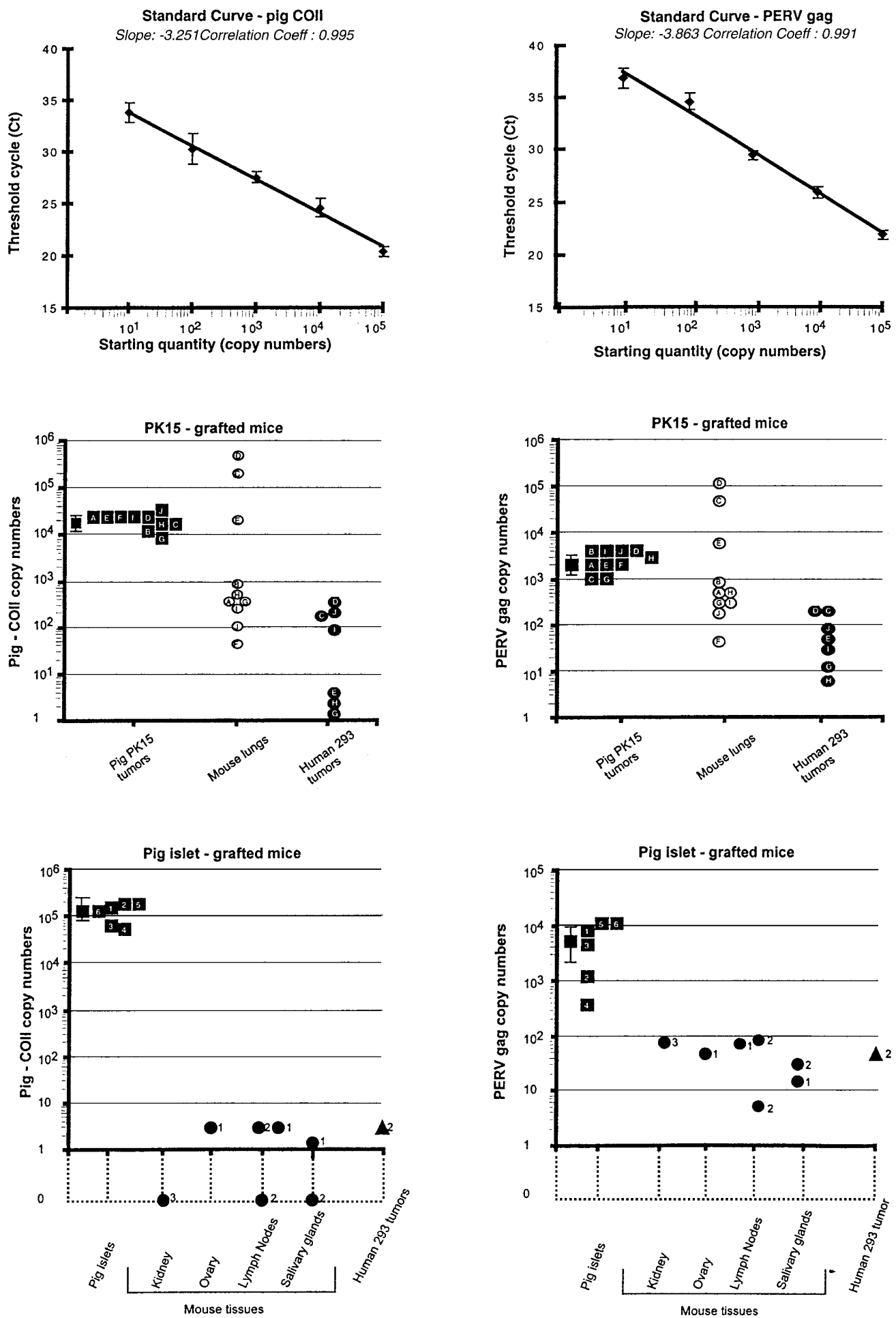

Fig. 3. Determination of copy numbers of PERV-gag and pig mt COII DNA by real-time PCR in nude mice concomitantly grafted with human 293 cells and PERV-producing PK15 cells or pig islet cells. Standard curves were constructed for gag and mt DNA, using serial dilutions of plasmids containing the gag or mt insert. The numbers of copies versus "threshold cycle" (Ct) are plotted on each standard curve. For mice grafted with PK15 cells, panels represent the individual results obtained for PERV-gag and pig mt COII with mouse lung or human 293 tumour, respectively (PERV-positive detection by classical

PCR). For nude mice grafted with pig islet cells, panels represent the individual results obtained for gag and pig $\mathrm{mt}$ with the seven mouse tissues and one human 293 tumour, respectively (PERV-positive detection by classical PCR). The number or letter allocated to a given mouse in each symbol serves as a reference mark between panels for PERV-gag and pig mt. Squares correspond to the "reference" values obtained from pig PK15 tumours or pig islet cells (the mean values \pm SEM are also shown) 
ples were tested with quantitative PCR. The mean P-to-M ratio calculated for these tumours $(4.68 \pm 2.45)$ differed from the reference ratio for PK15 tumours $(p \leq 0.005)$. All these human tumours had a P-to-M ratio higher than the mean $+3 \mathrm{SD}$ of the ratio for PK15 tumours.

Mice grafted with SPF pig islet cells and human 293 cells. PERV and mitochondrial sequences in the five islet cell preparations grafted numbered $5722 \pm 3725$ and $111946 \pm 32325$ for each ng of DNA, respectively. The corresponding ratio of $0.05 \pm 0.03$ was used as the reference ratio.

Only the seven gag-positive mouse tissues were tested with quantitative PCR. Of the three gag DNApositive lymph nodes, one (from mouse No. 1) contained 78 PERV-gag and three COII copies (P-to-M ratio: 26). Another lymph node (from mouse No. 2) contained 101 PERV-gag and three COII copies (P-to-M ratio: 34). The third lymph node (also from mouse No. 2) contained four PERV-gag copies but no COII copies. Among the two gag-positive salivary glands, one contained 14 PERV-gag copies and one COII copy (mouse No. 1), and the other (mouse No. 3$) 28$ PERV-gag copies, but no COII copies. The ovary sample from mouse No. 1 contained 46 PERV gag copies and three COII copies (P-to-M ratio: 15). The kidney sample from mouse No. 3 contained 69 PERV gag copies but no COII copies.

The detection of PERV and mitochondrial sequences by classical PCR in one human 293 tumour (mouse No. 2) from islet cell-grafted mice (see above) was confirmed by quantitative PCR, ie. 47 copies of gag and three copies of COII were found. This corresponded to a P-to-M ratio of 16 , which was higher than the reference ratio. Mouse No. 2 also had two gag-positive lymph nodes.

After in vitro phagocytosis of pig islet cell lysates, PERV compared to pig $\mathrm{mt}$ sequences in plastic-adherent spleen cells from nude irradiated mice $(n=7)$ numbered $427 \pm 191$ vs $8250 \pm 3689$ (P-to-M ratio: $0.21 \pm 0.11$ ).

\section{Discussion}

The ability of PERV produced by pig cell lines or primary cell cultures to infect human cells in vitro has been documented $[8,9,13,14,15,16]$, and serial passages of PERV on a human cell line have produced retroviruses with a higher tropism for human cells [17]. Our previous work found that pancreas expressed the lowest PERV mRNA levels in SPF pig tissues intended for grafting [5] and that long-term follow-up failed to detect in vitro transmission of PERV from SPF pig islets to a panel of human cells (including very permissive 293 tumour cells), even after repeated and optimised co-incubations [8]. Conversely, the same target human cells were infected after co-in- cubation with PK15 or G2 cells. These results indicate that pig islets have very little probability of transmitting PERV to human cells in vitro. However, the actual risk of infection during pig tissue xenografts can only be evaluated convincingly by in vivo experiments. Investigations performed in vivo in baboons $[21,22,23]$ and patients transplanted with pig tissues $[24,25,26,29]$ failed to detect transmission of pig retroviruses. Some recent studies have suggested that PERV could be transmitted to mice after pig islet xenografts [31, 32], although contradictory results have also been reported [30].

In this study, an original in vivo mouse model was designed to determine the actual risk of infection during pig pancreatic islet xenografts. Immunodeficient nude mice injected subcutaneously with cells of the human 293 line developed human tumours. These mice were then grafted with SPF pig islets or PK15 cells. They were killed after several weeks and nucleic acids were extracted from the human tumours and different mouse tissues. The infection of these samples was monitored by PCR and RT-PCR to detect PERV DNA and RNA for gag, pol and the 3 env sub-types (A, B and C) [13, 18]. Long PCR and RT-PCR were performed to detect full-length PERV proviruses and genomic RNA, respectively [8, 20]. As detection of PERV sequences in mouse or human cell extracts could be due to the presence of residual pig cells and not to infection, sensitive and specific detection of pig mt COII DNA was performed. COII PCR was at least 40 times as sensitive as that of PERV-gag. Real-time quantitative PCR for PERV-gag and pig COII DNA was performed to quantify absolute values of copy numbers, and ratios of both signals were established and compared to check ratios obtained in grafted pig cells.

Among the mouse tissues tested in PK15-injected nude mice, $79 \%$ were positive for PERV sequences, showing particularly high frequency and intensity of positivity in lung, testis, and lymph node. However, pig COII was also detected in most (92\%) of these mouse samples, indicating pig cell microchimerism. Quantitative PCR showed that the PERV-to-COII ratios for lung, lymph node, salivary gland, heart, kidney and testis from PK-15 grafted mice were significantly higher than the control ratio for explanted PK15-tumours. These results strongly suggest that PERV infection as well as microchimerism occurred in these tissues. The existence of PERV transmission was further substantiated by detection of full-length PERV sequences and PERV RNA in most of these tissues. Thus, PERV proviruses could remain competent for replication once integrated into the mouse genome. However, a recent study reported that normal or chemically immunosuppressed rats remained uninfected by PERV after intraperitoneal inoculation of PK15 cells [33]. This discrepancy could be due to the choice of animal models and the fact that the state of the immune 
system is not the same in immunosuppressed rats and nude mice or differences in the mode of PK15 cell administration or both. Concerning the last point, longterm PK15 grafts in our model seem more closely related to the circumstances of xenotransplantation than a single PK15 cell injection. Moreover, most human 293 tumours that developed in PK15-injected nude mice in our study were positive for both PERV and COII sequences, and env DNA, full-length PERV and PERV RNA were detected in most of these tumours. Quantitative PCR showed that the PERV-to-COII ratio of these human tumours was significantly higher than the control ratio in PK15-tumours. These results provide the first strong evidence that transmission of PERV sequences from PK15 cells to human 293 cells occurs in vivo in addition to microchimerism.

Similarly, PERV sequences occurred in pig islet-injected nude mice bearing human tumours generated by the 293 cell line. Among 41 mouse tissues tested, only seven (from three mice) showed detectable PERV sequences. Four of these 7 PERV-positive tissues (salivary gland from mouse No. 1, lymph node from mouse No. 2, and salivary gland and kidney from mouse No. 3) were negative for porcine COII DNA. As COII PCR is at least 40 times as sensitive as PERV PCR, it is not likely that absence of COII was a falsenegative result. Instead, these findings, which were confirmed by quantitative PCR, suggest that PERV infection occurred in these four tissues in the absence of microchimerism. Moreover, three other mouse tissues (salivary gland and ovary from mouse No. 1 and lymph node from mouse No. 2) were positive for both PERV and COII DNA. Quantitative PCR showed that the PERV-to-COII ratios for these three tissues were higher than the PERV-to-COII ratio for grafted pig islets. This suggests that the three tissues were also infected by PERV. In contrast to findings for PK15-injected mice, no PERV RNA was detected in tissues of pig islet-injected mice. This suggests that the PERV infection obtained in pig islet-injected mice could have been unproductive. Moreover, in contrast to the high frequency and intensity of PERV positivity in lung of PK15-injected mice, all lung samples of pig islet-injected mice were negative for both PERV and COII DNA. One possible explanation for this is that PERV produced by PK15 cells could differ in tropism from that produced by pig islets. Furthermore, all but one of the human 293 tumours obtained in islet-injected nude mice were positive for pig COII sequences, which indicates that pig cell microchimerism was obtained not only in mouse tissues but also in the human tumours of these mice. A unique but noteworthy event was the occurrence of PERV sequences in a human tumour obtained from mouse No. 2, which also had two PERV-positive lymph nodes. Quantitative PCR showed that the PERV-to-COII ratio for this tumour was higher than the control ratio for grafted pig islets, which suggests that human cells were infected by PERV in this mouse. This might seem discordant with the results for our previous study, which failed to detect in vitro transmission of PERV from SPF pig islets to human cells, including the human 293 line. Several complex mechanisms occurring in vivo could account for this apparent discrepancy. Pig islets injected into mice could be subjected to reactivation of PERV sequences and release infectious particles. Or the passage of PERV from pig islets to mouse cells could change the tropism, ie. PERV produced from mouse cells could be able to infect human cells. However, even though surviving pig islet cells remained at the time of killing, the P-to-M ratio in plastic-adherent mouse cells after in vitro phagocytosis of pig islet cells does not reveal greater phagocytose of PERV DNA than pig mt DNA, and phagocytosis potency was reduced in irradiated nude mice, caution must be taken to avoid misinterpretation of the results. If part of the islet-cells were destroyed, it cannot be completely excluded that islet cell debris could have been phagocytosed by cells that could home to mouse tissues thereby complicating the analysis of pig DNA sequences in these tissues.

In conclusion, PERV produced by PK15 cells was able to infect various mouse tissues. Moreover, extensive pig cell chimerism was obtained in these tissues, indicating the circulation of porcine cells. Our study also provides the first evidence for infection of human 293 cells by PERV in vivo in this mouse model. Additionally, it indicates that transmission of PERV sequences from SPF pig islets to mouse tissues could have occurred. Finally, our study suggests for the first time that human 293 cells can be PERV-infected by pig islets in vivo. Taken together, these results tend to confirm the risk of PERV transmission in vivo from pig tissues to humans during xenotransplantation.

Acknowledgements. This work was supported by grants from the Pays de la Loire and Brittany regions. SPF pig tissues were obtained by collaboration with AFSSA (Ploufragan, France). The authors thank Dr E. Gouin for providing isolated pig islets. They also thank Mrs S. Pogu for her excellent technical support.

\section{References}

1. Gouin E, Rivereau AS, Darquy S et al. (1997) Minimisation of microbial contamination for potential islet xenografts using specific pathogen-free pigs and a protected environment during tissue preparation. Diabetes Metab 23: 537-540

2. Gouin E, Rivereau AS, Duvivier V et al. (1997) Perifusion analysis of insulin secretion from specific pathogen-free large-white pig islets shows satisfactory functional characteristics for xenografts in humans. Diabetes Metab 24: 208-214

3. Rivereau AS, You S, Lalain S, Gouin E, Saï P (1998) In vitro xenorecognition of adult pig pancreatic islet cells by splenocytes from nonobese diabetic or non-diabetes-prone mice. Transplantation 66:633-638 
4. You S, Gouin E, Saï P (1998) Lymphocytes from NOD mice fed with pig cells displayed modified proliferation and lowered aggressiveness in vitro against pig islets. Diabetologia 41:955-962

5. Clémenceau B, Lalain S, Martignat L, Saï P (1999) Porcine endogenous retroviral mRNAs in pancreas and a panel of tissues from specific pathogen-free pigs. Diabetes Metab 25:518-525

6. Lalain S, Chaillou L, Gouin E, Saï P (1999) Intensity and mechanisms of in vitro xenorecognition of adult pig pancreatic islet cells by CD4+ and CD8+ lymphocytes from type I diabetic or healthy subjects. Diabetologia 42:330 335

7. You S, Rivereau AS, Gouin E, Saï P (2001) In vitro coincubation of pig islet cells with spleen cells from non obese diabetic mice causes decrease of insulin release during perifusion: involvement of non T-cell and T-cell-mediated xenogeneic mechanisms. Clin Exp Immunol 123:1-8

8. Clémenceau B, Jegou D, Martignat L, Saï P (2001) Longterm follow-up failed to detect in vitro transmission of fulllength porcine endogenous retroviruses from specific pathogen free pig islets to human cells. Diabetologia 44:1750-1756

9. Patience C, Takeuchi Y, Weiss RA (1997) Infection of human cells by an endogenous retrovirus of pigs. Nat Med 3:282-286

10. Patience C, Switzer WM, Takeuchi Y et al. (2001) Multiple groups of novel retroviral genomes in pigs and related species. J Virol 15:2771-2775

11. Ericsson T, Oldmixon B, Blomberg J, Rosa M, Patience C, Andersson G (2001) Identification of novel porcine endogenous beta retrovirus sequence in miniature swine. J Virol 15:2765-2770

12. Mang R, Maas J, Chen X, Goudsmit J, Van der Kuyl AC (2001) Identification of a novel type C porcine endogenous retrovirus: evidence that copy number of endogenous retroviruses increases during host inbreeding. J Gen Virol 82: 1829-1834

13. Le Tissier P, Stoye JP, Takeuchi Y, Patience C, Weiss RA (1997) Two sets of human-tropic pig retrovirus. Nature 389:681-682

14. Takeuchi Y, Patience C, Magre S et al. (1998) Host range and interference studies of three classes of pig endogenous retrovirus. J Virol 72:9986-9991

15. Martin U, Kiessig V, Blusch JH et al. (1998) Expression of pig endogenous retrovirus by primary porcine endothelial cells and infection of human cells. Lancet 352:692-694

16. Wilson CA, Wong S, Muller J, Davidson CE, Rose TM, Burd P (1998) Type C retrovirus released from porcine primary peripheral blood mononuclear cells infects human cells. J Virol 72:3082-3087

17. Wilson C, Wong S, VanBrocklin M, Ferderspiel M (2000) Extended analysis of the in vitro tropism of porcine endogenous retrovirus. J Virol 74:49-56

18. Akiyoshi DE, Denaro M, Zhu H, Greenstein JL, Banerjee P, Fishman JA (1998) Identification of a fulllength cDNA for an endogenous retrovirus of miniature swine. J Virol 72:4503-4507

19. Tacke SJ, Kurth R, Denner J (2000) Porcine endogenous retroviruses inhibit human immune cell function: Risk for xenotransplantation? Virology 268:87-93

20. Bösch S, Arnauld C, Jestin A (2000) Study of full-length porcine endogenous retroviral genomes (PERVs) with envelope gene polymorphism in a specific-pathogen-free panel large white swine herd. J Virol 74:8575-8581
21. Martin U, Steinhoff G, Kiessig V et al. (1998) Porcine endogenous retrovirus (PERV) was not transmitted from transplanted porcine endothelial cells to baboons in vivo. Transpl Int 11:247-251

22. Loss M, Arends H, Winkler M et al. (2001) Analysis of potential porcine endogenous retrovirus (PERV) transmission in a whole-organ xenotransplantation model without interfering microchimerism. Transpl Int 14:31-37

23. Switzer WM, Michler RE, Shanmugam V et al. (2001) Lack of cross-species transmission of porcine endogenous retrovirus infection to nonhuman primate recipients of porcine cells, tissues, or organs. Transplantation 71:959965

24. Heneine W, Tibell A, Switzer WM et al. (1998) No evidence of infection with porcine endogenous retrovirus in recipients of porcine islet-cell xenografts. Lancet 352: 695-699

25. Patience C, Patton GS, Takeuchi Y et al. (1998) No evidence of pig DNA or retroviral infection in patients with short-term extracorporeal connection to pig kidneys. Lancet 352:699-701

26. Paradis K, Langford G, Long Z et al. (1999) Search for cross-species transmission of porcine endogenous retrovirus in patients treated with living pig tissue. Science 285: 1236-1241

27. Pitkin Z, Mullon C (1999) Evidence of absence of porcine endogenous retrovirus (PERV) infection in patients treated with a bioartificial liver support system. Artif Organs 23:829-833

28. Dinsmore JH, Manhart C, Raineri R, Jacoby DB, Moore A (2000) No evidence for infection of human cells with porcine endogenous retrovirus (PERV) after exposure to porcine fetal neuronal cells. Transplantation 70:1382-1389

29. Schumacher JM, Ellias SA, Palmer EP et al. (2000) Transplantation of embryonic porcine mesencephalic tissue in patients with PD. Neurology 54:1042-1050

30. Elliot RB, Escobar L, Garkavenko O et al. (2000) No evidence of infection with porcine endogenous retrovirus in recipients of encapsulated porcine islet xenografts. Cell Transplant 9:895-901

31. Deng YM, Tuch BE, Rawlinson WD (2000) Transmission of porcine endogenous retroviruses in severe combined immunodeficient mice xenotransplanted with fetal porcine pancreatic cells. Transplantation 70:1010-1016

32. Van der Laan LJ, Lockey C, Griffeth BC et al. (2000) Infection by porcine endogenous retrovirus after islet xenotransplatation in SCID mice. Nature 407:90-94

33. Specke V, Tacke S, Boller K, Schwendemann J, Denner J (2001) Porcine endogenous retroviruses: in vitro host range and attempts to establish small animal models. J Gen Virol 82:837-844

34. Weiser B, Nachman S, Tropper P et al. (1994) Quantification of human immunodeficiency virus type 1 during pregnancy: relationship of viral titer to mother-to-child transmission and stability of viral load. Proc Natl Acad Sci USA 91:8037-8041

35. Chaillous L, Darquy S, Maugendre S, Rivereau AS, Reach G, Saï P (1996) Xenograft of porcine islets immunoprotected in hollow fibres reduce the incidence of diabetes in non-obese diabetic mice. Diabetologia 39:523-529

36. Switzer WM, Shanmugam V, Heneine W (1999) Polymerase chain reaction assays for the diagnosis of infection with the porcine endogenous retrovirus and the detection of pig cells in human and nonhuman recipients of pig xenografts. Transplantation 68:183-188 